\title{
Sodium Secretion and Reabsorption in the Human Eccrine Sweat Gland*
}

\author{
Gary W. Cage † and Richard L. Dobson \\ (From the Division of Dermatology, University of Oregon Medical School, Portland, Ore.)
}

Eccrine sweat in humans is normally a hypotonic solution, the solutes of which consist mainly of sodium, chloride, potassium, lactate, and urea (1). The sodium and chloride concentrations increase with increasing sweat rate (2), and at moderate to high sweat rates, the sodium concentration is an adequate measure of tonicity (3).

It is generally presumed that sweat is elaborated by the secretory coil of the gland and altered during its passage down the duct (4). However, analysis of the physiology of the duct depends upon relatively precise knowledge of the nature of the fluid elaborated at the secretory coil (secretory fluid). Previous studies give values for the sodium concentration of the secretory fluid that are distinctly hypotonic $(2,5)$ or suggest that it is isotonic (6). Our studies in which we analyzed the relationship of rate of sodium excretion to sweat rate from the forehead give approximately isotonic values for the sodium concentration of the secretory fluid.

\section{Methods}

Six healthy men, ages 21 to 29 , were used as subjects. For 1 week before the experiment, the only exercise allowed was that necessary for the usual duties of a dermatology resident or laboratory assistant. The experiment was performed in April in Portland, Oregon, at which time the temperature was relatively cool. No dietary restrictions were imposed.

* Submitted for publication January 8, 1965 ; accepted April 8, 1965.

This study was supported by the following: U. S. Army Research and Development Command, Office of the Surgeon General, contracts DA-49-193-MC 2176 and 2184, and National Institutes of Health grant AM05655 and training grant 5-TI-AM-5300-4.

This work was presented in part to the Research Conference on Pathogenesis of Cystic Fibrosis of the Pancreas, September 1964, Bethesda, Md:

$\dagger$ Address requests for reprints to Dr. Gary W. Cage, Dermatology Branch, National Cancer Institute, Bethesda, Md. 20014.
The skin of the forehead was gently cleansed with soap and water, rinsed with ion-free distilled water, and air dried. Aluminum chambers with internal diameter of $3.8 \mathrm{~cm}$ as described by Schwartz and Thaysen (2) were secured to the skin with Weldwood contact cement. Two Whatman 540 filter papers, $3.7 \mathrm{~cm}$ in diameter, were removed from weighed plastic bottles and introduced into the chamber and sealed at time zero. The filter papers were collected and replaced in their weighing bottles, and fresh preweighed filter papers were inserted every 3 to 10 minutes depending upon an estimate of the volume of sweat being produced. The time required for changing the filter papers was usually less than 5 seconds. Eight to twelve collections were obtained from each subject.

The subjects, wearing swimming trunks, entered a room with temperatures ranging from about $95^{\circ}$ to $110^{\circ} \mathrm{F}$ and humidity around $40 \%$. By altering the temperature and humidity in conjunction with mild, moderate, and vigorous exercise in the form of calisthenics, varying sweat rates were produced. At some time during the experiments the subjects were encouraged to maximal tolerated exercise. Sweat rates were increased and decreased so as to preclude sweat rate being a function of time. The subjects were weighed before and after the experiment, but were allowed water ad libitum during the experiment. The maximal duration of the experiment was 75 minutes for one subject and 60 minutes for the other five.

Sweat volumes were determined by weight differences of the filter papers. The filter papers were then eluted with ion-free distilled water and the sodium concentrations determined on appropriate dilutions with a Perkin Elmer atomic absorption spectrophotometer. Suitable blanks were used for each subject. Recovery experiments in which $0.1 \mathrm{ml}$ of a $100 \mathrm{mEq}$ per $\mathrm{L}$ sodium chloride solution was introduced onto preweighed filter papers and carried through the determination procedure were within $5 \%$ of the expected value for sodium.

The derivation of the sodium concentration of the secretory fluid and assessment of activity of the duct was modified from Schwartz and Thaysen (2) and Gibson and di Sant'Agnese (5). If one presumes that a fluid of constant sodium concentration is produced by the coil and that no changes occur in its passage down the duct, then a plot of rate of sodium excretion versus sweat rate would be a straight line passing through the origin ( $A B$ in Figure 1). Reabsorption of sodium and water by the duct in the same concentration as that in the lumen of the secretory coil would not alter this curve.

$A C D$ is an idealized curve of sweat rate versus rate of sodium excretion as it occurs in man. It has an initial 
nonlinear portion (AC), but then becomes linear (DC). Such a curve is compatible with the hypothesis that sodium and water are reabsorbed by the duct but that the sodium is reabsorbed in greater concentration than that found in the secretory fluid. If sodium reabsorption reaches a maximum at point $\mathrm{C}$, reabsorption of water by the duct, presuming that it is a passive phenomenon secondary to and coupled with active sodium reabsorption, also reaches a maximum at this point. Any increment of sodium and water output by the coil beyond point $C$ is then unaltered by the duct, and the curve $C D$ becomes parallel to the theoretical curve $A B$. Thus, from the slope of the curve $C D$ the sodium concentration of the secretory fluid can be derived.

The vertical differences between the curves $A B$ and ACD are a measure of the rate of water free sodium reabsorption in the duct, and the maximal rate (EC) is measured at the negative $y$ intercept of the curve CD. If no water reabsorption occurs in the duct, this equals total sodium reabsorption. If water reabsorption does occur in the duct, that portion of the sodium reabsorbed which would bring the water reabsorbed to the same concentration as the secretory fluid would not be measured, but it would not affect the slope or intercepts of the curve $C D$.

The horizontal differences between the curves $A B$ and $\mathrm{ACD}$ reflect the free water clearance by the duct, and the maximal free water clearance $(F C)$ is measured at the $x$ intercept of the curve CD. This quantity does not assume exclusion of water reabsorption.

Rates of sodium excretion were plotted for each individual. By inspection, those points that fell beyond the initial nonlinear portion of the curve were used to fit the best straight line by the method of least squares (7). The slope of this line is given as the sodium concentration of the secretory fluid, the negative $y$ intercept is given as the maximal rate of water free sodium reabsorption, and the positive $x$ intercept is given as the maximal free water clearance.

\section{Results}

Sodium concentrations versus sweat rates for each individual are shown in Figure 2. Note that the scales used for sweat rate differ from subject to subject. Table I gives the range of sweat rates, the range of sodium concentrations in the sweat, and the approximate rate at which a given sodium concentration of $70 \mathrm{mEq}$ per $\mathrm{L}$ is produced (from Figure 2).

Figure 3 gives plots of sweat rate versus rate of sodium excretion. Note that the scales are not comparable from subject to subject. Table II gives the derived values for the sodium concentration of the secretory fluid, the maximal rate of water free sodium reabsorption in the duct, and the maximal free water clearance.

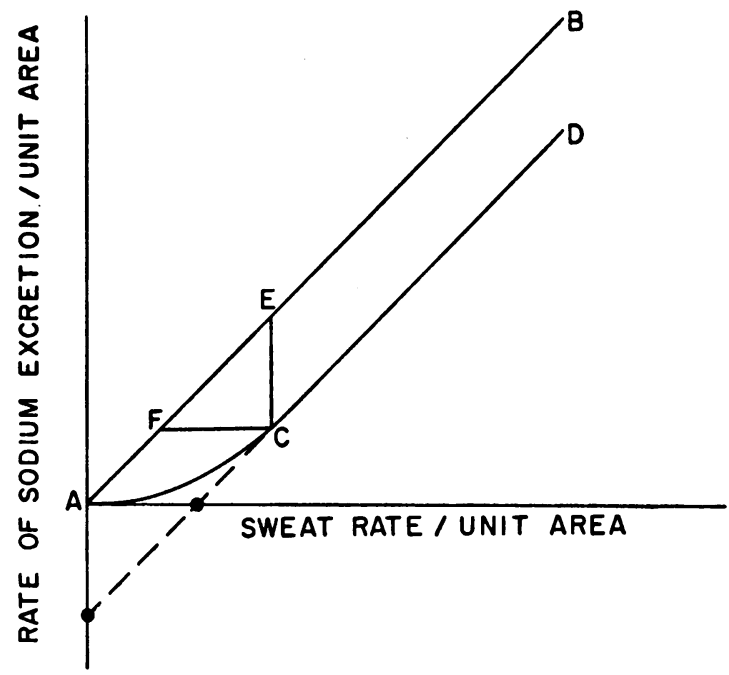

Fig. 1. Relationship of Rate of SODIUM EXCRETION to SWEAT RATE.

The wide variation of sodium concentration in sweat with sweat rate can be seen in Figure 2 and Table I. Although the stimuli eliciting sweat were not strictly comparable from subject to subject, i.e., some subjects could exercise more vigorously than others, the highest sweat rate was markedly variable. The highest sweat rate from one subject was less than $15 \%$ that of the most vigorous sweat producer. Nevertheless, at the highest sweat rates, the sodium concentrations were nearly comparable from subject to subject. The sweat rate at which a given sodium concentration of $70 \mathrm{mEq}$ per $\mathrm{L}$ was produced showed similar variation.

From the points on the curves in Figure 1, it would appear that if lower sweat rates were

\section{TABLE I}

Range of sweat rate and sodium concentration and approximate rate at which sodium concentration is $70 \mathrm{mEq}$ per $L$

\begin{tabular}{|c|c|c|c|}
\hline Subject & $\begin{array}{l}\text { Range of } \\
\text { sweat } \\
\text { rate }\end{array}$ & $\begin{array}{c}\text { Range of } \\
\text { sodium } \\
\text { concentration }\end{array}$ & $\begin{array}{c}\text { Sweat } \\
\text { rate at } \\
\text { which } \\
\text { sodium } \\
\text { concen- } \\
\text { tration } \\
\text { is 70 } \\
\mathrm{mEq} / \mathrm{L}\end{array}$ \\
\hline & $\mathrm{ml} / \mathrm{min} / \mathrm{m}^{2}$ & $m E q / L$ & $m l / m i n / m^{2}$ \\
\hline $\begin{array}{l}\text { PM } \\
\text { CS } \\
\text { SS } \\
\text { FP } \\
\text { MY } \\
\text { BB }\end{array}$ & $\begin{array}{l}6.7-65.6 \\
5.9-63.5 \\
7.2-45.1 \\
1.8-7.1 \\
1.7-17.9 \\
3.5-32.9\end{array}$ & $\begin{array}{l}43-111 \\
12-104 \\
19-85 \\
24-90 \\
10-91 \\
21-107\end{array}$ & $\begin{array}{r}28 \\
31 \\
36 \\
5 \\
15 \\
19\end{array}$ \\
\hline
\end{tabular}




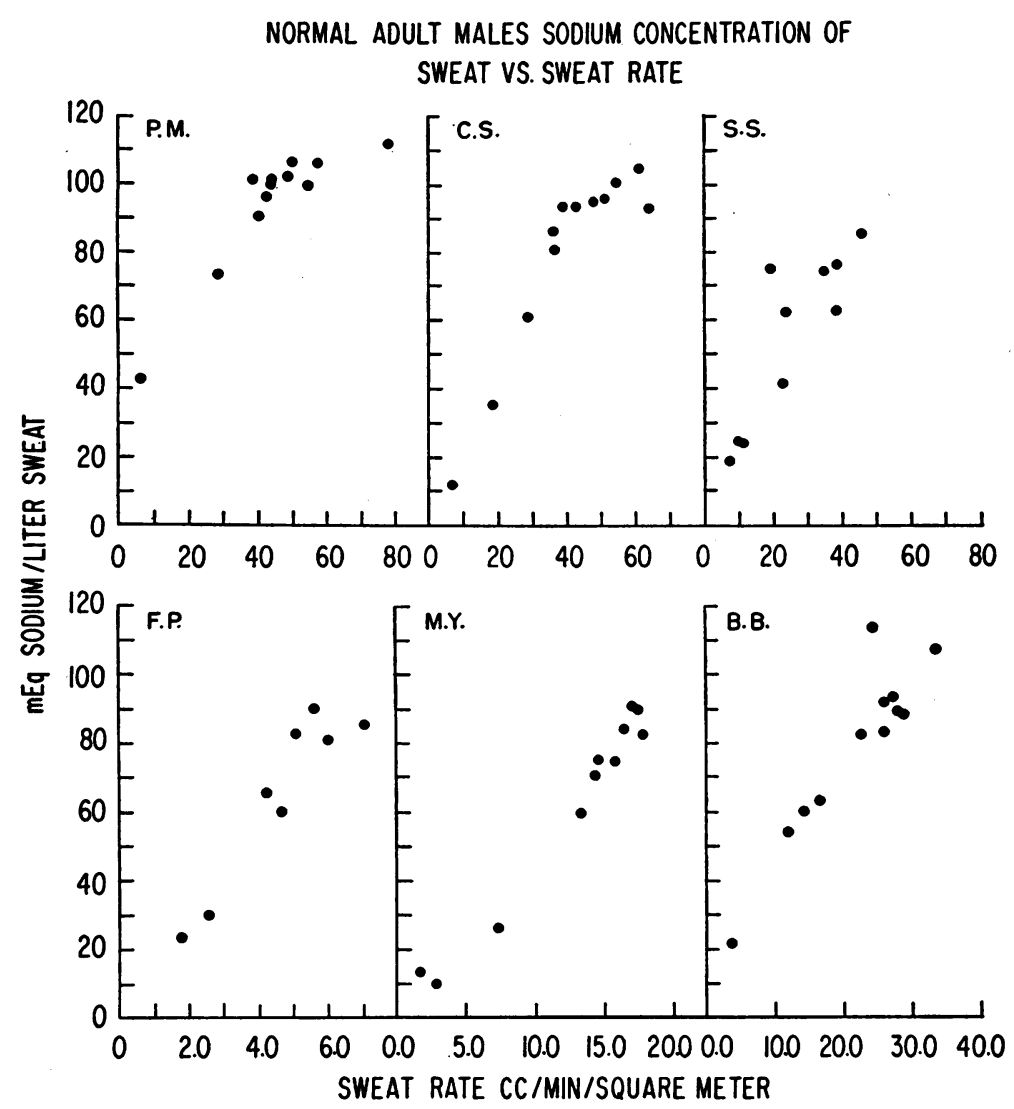

Fig. 2. Sodium concentration of sweat versus sweat rate. Note differences in scales.

elicited, even lower sodium concentrations could be produced.

The average value of the sodium concentration of the secretory fluid of $137.8 \mathrm{mEq}$ per $\mathrm{L}$ is in the isotonic range. Although the range of 117 to 172

TABLE II

Derived values for sodium concentration of secretory fluid, maximal rate of water free sodium reabsorption in the duct, and maximal free water clearance

\begin{tabular}{lccc}
\hline \hline Subject & $\begin{array}{c}\text { Sodium } \\
\text { concentra- } \\
\text { tion of } \\
\text { secretory } \\
\text { fluid }\end{array}$ & $\begin{array}{c}\text { Free } \\
\text { water } \\
\text { clearance }\end{array}$ & $\begin{array}{c}\text { Water } \\
\text { free } \\
\text { sodium } \\
\text { reabsorption }\end{array}$ \\
\hline PM & $m E q / L$ & $m l / m i n / m^{2}$ & $m E q / m i n / m^{2}$ \\
CS & 137 & 12.3 & 1.68 \\
SS & 134 & 13.8 & 1.84 \\
FP & 117 & 13.5 & 1.60 \\
MY & 122 & 1.9 & .23 \\
BB & 142 & 8.7 & 1.49 \\
Average & 137.8 & 10.0 & 1.45 \\
SD & 18.1 & & \\
\hline
\end{tabular}

$\mathrm{mEq}$ per $\mathrm{L}$ is wider than one would desire, this is perhaps a result of technical error and variation in statistically fitting the best line to the data.

The maximal rates of water free sodium reabsorption and maximal free water clearance appear to be widely variable from subject to subject and were not averaged.

\section{Discussion}

The forehead was selected as the site of collection since thermal sweating was noted earlier and at larger volumes at this site. Although this is also an area of high sebum production and contamination with sebum could introduce an error into the sweat weights, the maximal rate of sebum production from this area in adult males, as reported by Pochi, Strauss, and Mescon (8), is less than $1 \%$ of the lowest sweat rate recorded for any subject in our study.

Skin temperature, rectal temperature, and mus- 


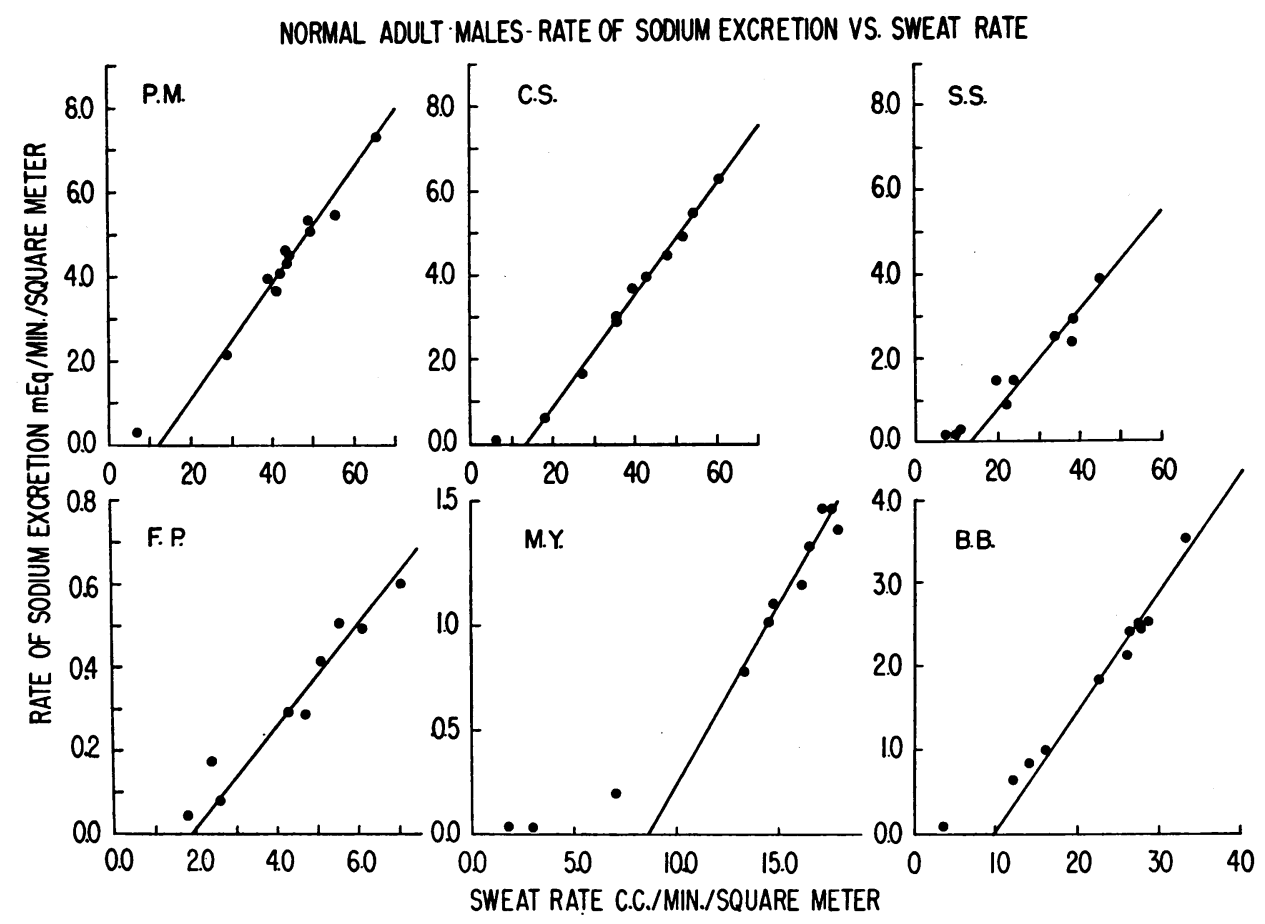

Fig. 3. RAte of SODium EXCREtion versus sweat RAte. Note differences in scales.

cular activity have been reported to affect the sodium or chloride concentration of sweat (1). However, in most of these studies, sweat rates were either not determined $(9,10)$ or were determined on portions of the body different from that at which the temperature was measured $(11,12)$, or the periods of collection were too long to allow definition of the acute relationship of sweat rate to solute concentration $(13,14)$. Locke, Talbot, Jones, and Worcester (15) found that sodium and chloride concentrations did vary with thermal stress, body temperature, and sweat rate, but that all of these factors were closely correlated with each other and that the sodium concentration was most closely correlated with sweat rate. Sodium concentrations increase with sweat rate if sweating is elicited by pharmacological stimulation alone (2). In our studies the rate of work was varied from collection to collection, and although not measured, surface temperature undoubtedly changed considerably during the experiment. We noted no significant deviations of the sodium concentrations that could be secondary to factors other than sweat rate. In acute experiments it seems unlikely that rectal or skin temperature, the intensity of heat stress, or muscular activity affects sweat sodium concentrations other than through their effect on sweat rate.

After several hours of profuse sweating, the sweat rate may decline with some increase in the sweat sodium concentration, a process that has been termed "sweat gland fatigue" (16). No evidence of this process is found in the data from the present study nor has it been reported as early as 75 minutes (16), the maximal duration of sweating in this experiment.

The moderate ambient temperatures and the restriction of exercise before the experiment make prior acclimatization unlikely (17). Acclimatization responses of the sweat gland during the experiment seem unlikely since sodium concentration of sweat has not been shown to change until about 12 hours after the beginning of an acclimatizing stress (17). At least 5 hours of continuous intravenous administration of aldosterone is necessary before significant lowering of sweat sodium occurs (18).

There was no evidence that any of the subjects had any known abnormality of adrenal cortical function or abnormality of the sweat glands (1).

The brief duration of the experiment was designed to minimize possible factors secondary to 
alterations in salt and water balance (17). The maximal weight loss by any subject was 1.25 pounds.

Others $(1-3,5,6)$ have pointed out the variation of sodium concentration with sweat rate. The figures given here serve only to emphasize how wide this variation can be and the relative lack of meaning of an isolated sweat sodium concentration from an adult without some reference to sweat rate. In addition, the sweat rate at which a given sodium concentration is produced varies considerably from individual to individual.

Our derived values for the concentration of sodium in the secretory fluid are higher than any of those previously reported for normal subjects by this method of analysis $(2,5)$. Our studies differ from these in that 1) thermal stimuli were used instead of pilocarpine iontophoresis, 2) the forehead was used instead of the forearm or other area, 3) a wider range of sweat rates was produced with generally higher sweat rates, 4) more collections were made from a single site, and 5) sodium concentrations were determined directly on each sample.

The precursor of the secretory fluid must be interstitial fluid or blood plasma. It is unlikely that the secretory fluid is an ultrafiltrate of plasma since 1 ) there is no morphological similarity to the renal glomerulus $(4), 2$ ) sweat can be produced even if the arterial supply is occluded (19), 3) glucose does not appear in sweat at high levels of glucosemia (20), and 4) creatinine and inulin are always found in concentrations less than those existing in plasma (21).

The alternative to filtration is that the secretory fluid is formed by active secretion. A hypotonic solution could be formed if water were actively secreted by the secretory coil, but since "nowhere in the animal kingdom is there a proved case of active water transport" (22) such a presumption is unwarranted. An alternative hypothesis of secretion is that an osmotically active molecule, e.g., sodium, is actively transported into the lumen of the coil from the interstitial fluid; because of the osmotic gradient established water and other components would then diffuse into the lumen of the coil from the interstitial fluid. Since the active transport of sodium across membranes with a secondary passive diffusion of water is known to occur, e.g., in the renal tubule (23), it would seem reasonable that such a mechanism might function in the secretory coil of the sweat gland. If the membrane is only partially permeable to water and insufficient time is available for equilibration with the interstitial fluid, this fluid would be hypertonic to interstitial fluid. If the membrane is completely permeable to water, then the secretory fluid would equilibrate with interstitial fluid and be isotonic. In no case could it be hypotonic. Our data are compatible with a process of active secretion of sodium across a membrane relatively permeable to water as the mechanism of formation of the secretory fluid. A filtration mechanism cannot be excluded by these data, but this seems unlikely for the reasons previously stated.

Bulmer and Forwell (6) studied the relationship of sweat rate to sodium concentration and derived values for the secretory fluid by extrapolating the sodium concentration to infinite sweat rate. Three of their five subjects gave values in the isotonic range; two were less than $100 \mathrm{mEq}$ per $\mathrm{L}$, but these were subjects in whom lower sweat rates were produced.

Additional evidence that the secretory fluid is not hypotonic has been recently provided by Brusilow and Gordes (24) and Slegers (25), who found slightly hypertonic values for this fluid by determining freezing point depressions on frozen microsections. In our analysis (Figure 1), if the experimental plots of sodium excretion rate versus sweat rate approach the theoretical slope of the secretory fluid asymptotically instead of becoming equal to it at a point, our figures might err on the low side. Thus, our data cannot rule out the possibility that this fluid is hypertonic, but are incompatible with significantly hypotonic solution.

The values for free water clearance and water free sodium reabsorption as calculated are variable from subject to subject. This variability probably reflects variations in the number of glands per unit area in addition to variations of reabsorptive capacities of the glands from individual to individual. Similar difference would probably be noted with different sites on the same individual.

It is not known with certainty that water is reabsorbed in the duct of the sweat gland; however, the finding of sweat ureas consistently higher than plasma levels (1) suggests that water reabsorption does occur. Our data neither support nor deny the possibility, but if the presumptions of the mech- 
anism of reabsorption are valid, our data are valid whether water reabsorption occurs or not.

From physiological data alone it cannot be established that sodium reabsorption occurs in the duct and not in some portion of the coil. Evidence that this is the site at which reabsorption occurs is found in Munger and Brusilow's studies on the foot pad of the cat (26). Morphologically, the secretory portion of this gland is like that of the eccrine sweat gland of humans, but the duct is much shorter and its cells lack the mitochondria that are so numerous in the human gland. The sweat of the foot pad is slightly hypertonic and does not vary with sweat rate. Cryoscopic studies (27) show the fluid in the secretory coil to be essentially isosmotic to the sweat. This would then seem to be an example of a sweat gland with a functioning secretory coil but lacking ductal capacity for reabsorption.

\section{Summary}

The increase of sweat sodium concentration with increasing sweat rate is confirmed. In man values as low as 10 to 20 to over $100 \mathrm{mEq}$ per $\mathrm{L}$ can be produced on the forehead in the same individual by changing the sweat rate. The sweat rate at which a given sodium concentration occurs varies from individual to individual.

The sodium concentration of the fluid elaborated by the secretory coil was calculated as having a mean value of 137.8 (117 to 172 ) $\mathrm{mEq}$ per $\mathrm{L}$ and is in the isotonic range. We postulate that this fluid is formed by active secretion of sodium across the secretory coil with passive diffusion of water and other components through a relatively permeable membrane. However, a filtrative mechanism cannot be ruled out by these data.

The rate of water-free sodium reabsorption and free water clearance by the duct of the sweat glands of the forehead varies from individual to individual.

\section{References}

1. Robinson, S., and A. H. Robinson. Chemical composition of sweat. Physiol. Rev. 1954, 34, 202.

2. Schwartz, I. L., and J. H. Thaysen. Excretion of sodium and potassium in human sweat. $\mathrm{J}$. clin. Invest. 1956, 34, 114.

3. Adams, R., R. E. Johnson, and F. Sargent II. The osmotic pressure (freezing point) of human sweat in relation to its chemical composition. Quart J. exp. Physiol. 1958, 43, 241.
4. Montagna, W. The Structure and Function of Skin, 2nd ed. New York, Academic Press, 1962, p. 312.

5. Gibson, L. E., and P. A. di Sant'Agnese. Studies of salt excretion in sweat. Relationships between rate, conductivity, and electrolyte composition of sweat from patients with cystic fibrosis and from control subjects. J. Pediat. 1963, 62, 855.

6. Bulmer, M. G., and G. D. Forwell. The concentration of sodium in thermal sweat. J. Physiol. (Lond.) 1956, 132, 115.

7. Moroney, M. J. Facts From Figures, 2nd ed. London, Penguin Books, 1954.

8. Pochi, P. E., J. S. Strauss, and H. Mescon. Sebum secretion and urinary fractional 17 -ketosteroid and total 17-hydroxycorticoid excretion in male castrates. J. invest. Derm. 1962, 39, 475.

9. Lehmann, G., and A. Szakall. Weitere Untersuchungen über den Chlorumsatz bei Hitzarbeit. Arbeitsphysiologie 1939, 10, 608.

10. Henn, O. Der Chloridgehalt des Schweisses bei hoher Iemperatur, hoher relativ Feuchtigkeit, aber körplicher Ruhe. Arbeitsphysiologie 1953, 15, 93.

11. Johnson, R. E., G. C. Pitts, and F. C. Consolazio. Factors influencing chloride concentration in human sweat. Amer. J. Physiol. 1944, 141, 575.

12. Weiner, J. S., and R. E. van Heyningen. Relation of skin temperature to salt concentration of general body sweat. J. appl. Physiol. 1952, 4, 725.

13. Robinson, S., S. D. Gerking, E. S. Turrell, and R. K. Kincaid. Effect of skin temperature on salt concentration of sweat. J. appl. Physiol. 1950, 2, 654.

14. Lee, D. H. K., R. E. Murray, W. J. Simmonds, and R. G. Atherton. The effect of exercise in hot atmospheres upon the salt- and water balance of human subjects. Med. J. Aust. 1941, 2, 249.

15. Locke, W., N. B. Talbot, H. S. Jones, and J. Worcester. Studies on the combined use of measurements of sweat electrolyte composition and rate of sweating as an index of adrenal cortical activity. J. clin. Invest. 1951, 30, 325.

16. Sargent, F. Depression of sweating in man: socalled "sweat gland fatigue" in Advances in Biology of Skin, W. Montagna, R. A. Ellis, and A. F. Silver, Eds. New York, Pergamon Press, 1962, vol. 3 , p. 127.

17. Conn, J. W. Aldosteronism in man. Some clinical and climatological aspects. Part I. J. Amer. med. Ass. 1963, 183, 77.

18. McConahay, T. P., S. Robinson, and J. L. Newton. $d$-Aldosterone and sweat electrolytes. J. appl. Physiol. 1964, 19, 575.

19. Collins, K. J., F. Sargent, and J. S. Weiner. The effect of arterial occlusion on sweat-gland responses in the human forearm. J. Physiol. (Lond.) 1959, 148, 615.

20. Lobitz, W. C., Jr., and A. E. Osterberg. Chemistry of palmar sweat. III. Reducing substances (glucose). Arch. Derm. 1947, 56, 819.

21. Thaysen, J. H., and I. L. Schwartz. The perme- 
ability of human sweat glands to a series of sulfonamide compounds. J. exp. Med. 1953, 98, 261.

22. Gottschalk, C. W. Osmotic concentration and dilution of the urine. Amer. J. Med. 1964, 36, 670.

23. Giebisch, G., and E. E. Windhager. Renal tubular transport of sodium, chloride and potassium. Amer. J. Med. 1964, 36, 643.

24. Brusilow, S. W., and E. H. Gordes. Determination of sweat gland precursor fluid osmolality by direct cryoscopy (abstract). J. clin. Invest. 1963, 42, 920.
25. Slegers, J. F. G. The mechanism of eccrine sweatgland function in normal subjects and in patients with mucoviscidosis. Dermatologica (Basel) 1963, 127, 242.

26. Munger, B. L., and S. W. Brusilow. An electron microscopic study of eccrine sweat glands of the cat foot and toe pads. J. biophys. biochem. Cytol. 1961, 11, 403.

27. Brusilow, S. W., and B. Munger. Comparative physiology of sweat. Proc. Soc. exp. Biol. (N. Y.) 1962, 110, 317. 